\title{
Im Bild
}

Erhard Taverna

\section{Moderne Stühle im Wartezimmer, exotische Pflanzen, ein Farbkonzept und natürlich neue Bilder.}

Schönes, und die öffentliche Anerkennung und Aufmerksamkeit sorgen für die beabsichtigte Werbung. Hier hilft mir niemand, es gibt keine Kommission, die das Auswählen und Verhandeln besorgt. So bleibt es beim Vorsatz, wie mit anderem auch. Mit der Zeit habe ich meine Helgen gar nicht mehr gesehen, sie waren einfach da, sonst nichts. Nur die bunten Seiten des Pharmakalenders über dem Empfang sorgten für Abwechslung. Die waren ja auch schön frech, manchmal. Das illustrierte Zeug ist ein Staubfänger, wie der ganze Rest, den am Donnerstag ein Wischlappen fegt.

Der neue Wandschmuck ist eine notwendige und wirksame Massnahme. Der Doktor hat sich doch ganz

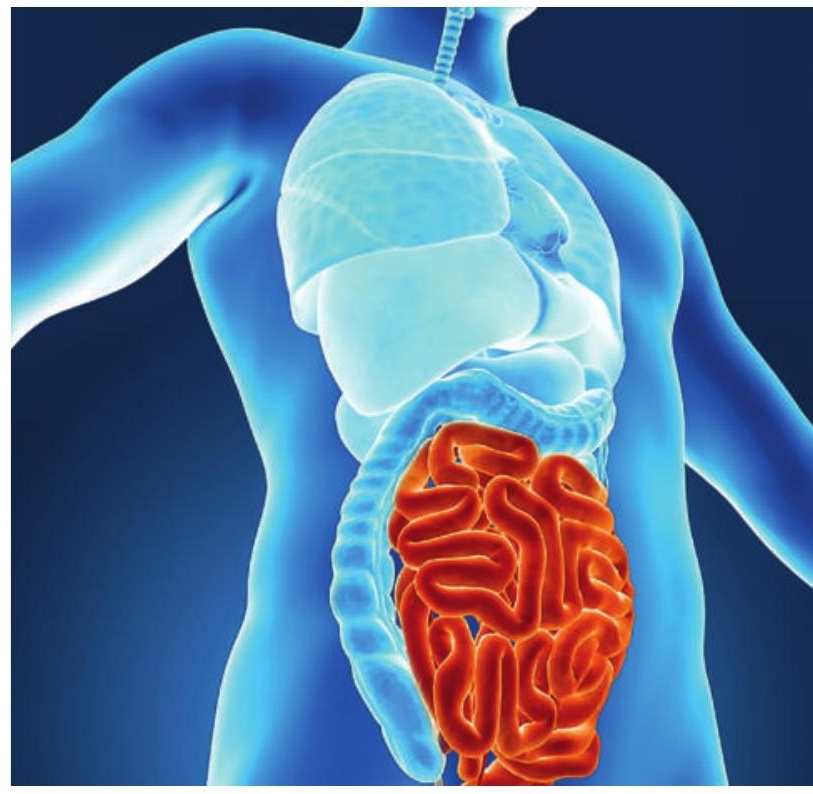

gut gehalten, etwas grau und weiss stehen ihm nicht schlecht, das muss man zugeben. Doch die Diplome entsorgt er leichten Herzens, zu offensichtlich ist der zunehmende Abstand zu den Abschlussjahren. Im Flur stapeln sich die eingetroffenen Pakete. Anatomische Schautafeln. Warum nicht, er weiss nicht mehr, wie er darauf gekommen ist. Egal, jetzt hängen die Bilder über der Treppe ins Untergeschoss. Alle möglichen Schnitte durch menschliche Körper, in schwarz eloxierten Alurahmen, quer über alle Räume verteilt. Rote und blaue Gefässbäume, bunte Organe, beschriftete Muskeln über gelblichen Knochen, lehrreich und ästhetisch. Heutigen Kunden ist das zumutbar. Nichts Gruseliges, nur sauber und übersichtlich ausgelegte Innereien eines komplizierten Apparates, den geschickte Hände zuverlässig wieder zusammenfügen. Modellaufnahmen eines fachgerechten Handwerkers, was gut in seine nüchterne, rationale Werkstatt passt. Der Totenschädel, lange Jahre ein stummer Zuschauer im Büchergestell hinter dem Schreibtisch, geniert ihn. Seine Botschaft ist nicht mehr zeitgemäss. Er ersetzt den Kopf mit Leonardo da Vincis Bild des vitruvianischen Mannes. Ein aufrecht stehender, kräftiger, nackter Mann, eingefügt in die Geometrie eines Quadrats und eines Kreises. Die Figur trifft man häufig in Schönheitskliniken. Harmonie und Fitness, darauf kommt es heute an. Ein optimistischer Endpunkt im Sprechzimmer. So sieht er das und fühlt sich belebt.

Meine neue Praxishilfe ist krank. Sie lacht nicht mehr, etwas wie Angst verdüstert ihre Züge. Einmal, als sie 
abends am Mikroskop arbeitete, die letzten Patienten waren gegangen, schrie sie plötzlich erschrocken auf. Unter vier Augen darauf angesprochen, ist sie in Tränen ausgebrochen. Sie sprach leise und verwirt von Bildern, die sich bewegten. Ich verstand nicht, was sie meinte. Da half alles nichts. Sie hat noch während der Probezeit gekündet. Noch weniger verstehe ich das Verhalten meiner langjährigen Angestellten, die wöchentlich die Praxis reinigt. Eine robuste, fleissige, verschwiegene Person, die auch an anderen Orten putzt. Sie war regelrecht empört und faselte etwas von Blut und immer wieder aufnehmen und abwischen. Was soll das? Schliesslich kann bei einer der vielen Blutentnahmen auch mal etwas auf den Boden tropfen. Ich habe es nachgeprüft und fand nur einige übersehene, schwarz vertrocknete Flecken. Auch einige Rahmen der neuen Bilder waren schwarz verklebt. Das konnte ich mir weniger erklären. Nachts, nach einem Notfall, war ich so müde, dass die Augen brannten. Als ich im Halbdunkel durch den Gang schritt sah es aus, als würde ein Fuss unter dem Rahmen hindurch den Boden abtasten. Eine Hand wühlte in den eigenen Eingeweiden. Ich hielt mich am Geländer fest. Verrückt, was so ein Schlafmangel vortäuscht. Ich habe danach traumlos bis weit in den Morgen geschlafen. Die Fortbildung liess ich sausen.

\section{Mit geweiteter Pupille habe er die Sitzenden angeglotzt.}

Allmählich bleiben die Patienten aus. Heiklen Aussprachen geht man hier aus dem Weg. So spricht kaum jemand über die Gründe seines Fernbleibens. Die meisten verschwinden einfach, als wären sie nie hier gewesen. Die Wenigen, die sich aufraffen, drucksen verlegen herum, als müssten sie etwas Unanständiges berichten. Es ist auch unerklärlich, obszön und widernatürlich, wenigstens aus ihrer Sicht. Da liegt angeblich beim Warten plötzlich eine Niere auf dem Tisch, und was wie ein langes, dürres Blatt im Ficus hängt, sei beim näheren Hinsehen eine Darmschlinge gewesen. Unerhörtes geschieht. Ein Augapfel mit anhaftenden Muskeln balanciert plötzlich auf dem äussersten Rand eines Heftstapels. Mit geweiteter Pupille habe er die Sitzenden angeglotzt. Den Ausschlag gab die Hand in der Spielsachenkiste. Bei Kindern verstehen die Leute keinen Spass. Zuerst habe sie es für einen Jux gehalten, dann aber deutlich gesehen, wie das Ding mit weissen Fingern nach der Puppe ihrer Kleinen griff. Die Mütter gehen als erste.

Eigentlich ist es mir egal, dass weniger Leute in die Praxis kommen. Ohne Hilfe am Empfang und im Labor habe ich auch so noch mehr als genug zu tun. Was mich stört ist das Geschwätz im Dorf. Man könnte glauben, die Praxis sei eine Geisterbahn. Inzwischen ist es sehr still geworden. Ich bin schon beim Warten auf der Liege in meinem Sprechzimmer eingeschlafen. Eines Abends beim Diktieren, ich lasse das Zeugs jetzt auswärts schreiben, ist mir beim Vitruvmann etwas aufgefallen: Er kehrte mir den Rücken zu! Auch die geputzten Brillengläser änderten nichts daran. Merkwürdig. Ich behalte das vorläufig für mich. Doch bevor ich die Lichter löschte, schaute ich mir alle Bilder genauer an. Manche hatten sich tatsächlich verändert. Sie waren irgendwie plastischer geworden, drückten das Plexiglas nach aussen, waren näher an den Bildrand gerückt, als suchten sie dort einen Ausgang. Optische Effekte, die mir das Designerbüro erklären muss. Doch die behaupteten, sie hätten nie Bilder bestellt, geschweige denn geliefert. Eine Rechnung habe ich tatsächlich nie erhalten. Angst? Nein, habe ich nicht. Werde diese Phänomene mit wissenschaftlicher Distanz angehen, objektiv, unaufgeregt. Übrigens hat sich der Vitruvmann wieder umgekehrt. Als ich ihn fixierte, bewegte er Arme und Beine. Ein Hampelmann, der etwas mitteilen möchte. Zum Glück habe ich jetzt viel Zeit. Einige Bildflächen sind inzwischen leer. Man könnte sagen, die früheren Bewohner hätten die Flucht ergriffen. Gestern sass ein kopfloser Rumpf auf dem Toilettensitz und betätigte immer wieder die Wasserspülung. Jedes Organ benimmt sich so, als wäre es ein Ganzes. Wie könnten sonst ein Uterus und seine Adnexe mit Reagenzgläsern hantieren? Der Vitruvmann sitzt seit gestern auf der Pultkante und erklärt sich. Weiterschreiben macht jetzt keinen Sinn mehr. Es gibt Gescheiteres zu tun.

Er bleibt verschollen. Ausser dem abgeschlossenen Tagebuch hat die Spurensicherung keine weiteren Hinweise vorgefunden. Für Wahnvorstellungen ist nicht die Polizei zuständig. Der Untersuchungsrichter will den Fall vorläufig zu den Akten legen. Die Fahndung läuft. Früher oder später wird der Vermisste wieder von selber auftauchen. Bestimmt abgehauen, vermuten viele, da lief ja nichts mehr. Man kennt das von anderen Männern in der Midlife-Crisis. Ungeklärt ist der Verbleib zahlreicher Bilder, deren Vorhandensein von vielen Zeugen bestätigt wurde. Ein Kind will einen grauen Lieferwagen gesehen haben, der vor dem Haus mit vollem Laderaum wegfuhr. Die Vermisstenanzeige kam übrigens von der Putzfrau, sie hatte die Praxis als letzte betreten. Scheint auch nicht recht im Kopf zu sein. Das psychiatrische Gutachten erwähnt eine posttraumatische Störung. Den Doktor habe sie nach mehrmaligem Rufen in einem Bild entdeckt. Reglos, wie gemalt, Hand in Hand mit dem Vitruvmann als Begleiter. Sie kenne die Figur, er habe sie ihr einmal erklärt. Sein Arztkoffer sei neben ihm gestanden, er habe ihr lächelnd zugewinkt. So ein Blödsinn. 